\title{
DOES PREFERENCE FOR SONS HAVE A DIFFERENTIAL IMPACT ON THE INTELLIGENCE OF BOYS AND GIRLS?: EVIDENCE FROM INDIA
}

\author{
Gayatri RAINA'), Prahbhjot MALHI'), \\ ${ }^{1)}$ Himachal Pradesh University, India, ${ }^{2)}$ Post Graduate Institute of Medical Education and Research, India,
}

Dalip MALHOTRA ${ }^{3)}$ and Jagat M. JERATH ${ }^{4)}$

${ }^{3)}$ Himachal Pradesh University, India and ${ }^{4)}$ Panjab University, India

\begin{abstract}
The paper examined the impact of stated son preference on the intelligence of boys and girls from a developing country. It was hypothesized that preference for sons enhances the intelligence among boys whereas it hampers the intelligence of girls. The sample comprised of 204 boys and 213 girls studying in grade 6 to 8 in an urban centre of the state of Himachal Pradesh, India. A detailed questionnaire was administered to mothers which elicited information on the socio-economic characteristics of the household. The Coombs IS Index was used to measure son preference. Intelligence of the children was measured by the Standard Progressive Matrices and the $z$-scores were used as the dependent measure. Multiple regression analysis indicated that household income and son preference were positively correlated with the intelligence of boys and explained 14 percent of the variance in intelligence. In contrast, son preference was negatively correlated with the intelligence of girls and along with education of mother explained 17.8 percent of variance in the intelligence of girls, It was concluded that son preference has a differential impact on the intelligence of boys and girls which appears to be mediated through several social, cultural, and economic pathways.
\end{abstract}

Key words: son preference, intelligence, family influences, sex/gender discrimination

Human intelligence is a product of an extremely complex interplay between genetic factors and environmental conditions (Plomin, 1989; Weinberg, 1989). However, great disagreement exists concerning the relative contribution of each of these factors. Several lines of research offer support for the view that heredity plays a significant role in human intelligence. The prediction that the more closely two persons are related, the more similar their IQs will be has been confirmed. Bouchard and his colleagues (Bouchard, 1987; Bouchard, Lykken, McGue, Segal, \& Tellegan, 1990) tracked pairs of identical twins who were separated early in life and were raised in different homes. Since such persons were exposed to different environmental conditions a high correlation between the IQs suggested that heredity played a key role in intelligence. Additional support for the impact of heredity on intelligence is provided by studies involving adopted children. Evidence indicates that the IQs of adopted children resemble those of their biological parents more closely than those of their adoptive parents (Jencks, 1972: Munsinger, 1978).

Nevertheless, other findings have indicated that environmental variables, too, are of

Correspondence concerning this article should be addressed to Jagat M. Jerath, Department of Psychology, Panjab University, Chandigarh 160014, India (e-mail: jmjerath@cha.i91.net). 
great importance. One such finding is that IQ scores have risen substantially around the world at all age levels (Flynn, 1987). Since it seems very unlikely that massive shifts in human heredity have occurred during these decades, this rise can be interpreted only as stemming from environmental factors such as rising living standards, improved diets, and better educational opportunities for millions of human beings. Studies of environmental deprivation and environmental enrichment offer support for the important role of environmental factors. With respect to deprivation, it has been found that intelligence was reduced by the absence of certain forms of environmental stimulation early in life (Gottfried, 1984). A wide range of environmental factors which have found to be related to IQ scores are: nutrition (Galler, Ramsey, \& Forde, 1986), family background such as parents education and income (Jachuck, 1982; Chalip \& Stigler, 1986), and quality of education (Bouchard \& Segal, 1985).

The present study is concerned with the particular issue of the effect of parental socio-economic status and parents' sex preferences for children on the intelligence of boys and girls. It has been argued that in countries where son preference exists, female children are disadvantaged or discriminated against. Serious discrimination or outright neglect of female children has been documented in a number of studies, particularly In South Asia, the Middle East, and North Africa (Das Gupta, 1987; Hossain \& Glass, 1988; Basu, 1989; Miller, 1989; Kishore, 1995). Discrimination may affect care, educational opportunities, distribution of family resources including food, clothing, and medical care in favour of boys resulting in disproportionate malnutrition of female children (Chen, Huq, \& D'Souza, 1981; Gupta, 1986; Mankekar, 1988).

In the northern states of India, the evidence of gender based discrimination is so ubiquitous and pervasive that it results in excess female child mortality (Dyson \& Moore, 1983; Bourne \& Walker, 1991; Malhi, Jerath, \& Puri, 1991). Factors that account for the excess female child mortality in the country include differential allocations of food and health care, conscious neglect, female infanticide, and sex specific induced abortions (Ravindran, 1986).

Although substantial research on the prevalence of son preference and its impact on fertility and mortality has been conducted in India, no study to our knowledge, either in India or in the west, has investigated the impact of preference for sons on the intellectual performance of boys and girls. If discrimination against the girl child in breastfeeding, food in take, health care, nutrition and nourishment, and provision of material resources can lead to such a dramatic outcome as death, it should also have an impact on the intellectual growth of children. Keeping these points in view, the primary aim of the present study was to examine the impact of son preference on the intelligence of boys and girls, in an urban center of Himachal Pradesh, India. It was hypothesized that preference for sons enhances the intellectual performance among boys whereas it hampers the intellectual growth of girls. 


\section{METHOD}

The Setting:

Himachal Pradesh is a small hill state in the northern India accounting for only 0.62 percent of the population and 1.82 per cent of the area of India. Shimla, which is situated in the southern part of the state, is the capital city of Himachal Pradesh. Himachal Pradesh is one of the least populous states of the country having a population density of 93 persons per square $\mathrm{km}$. The crude birth rate and the crude death rate of the state were 27.9 and 8.8 per thousand population, respectively (Sample Registrar System, 1992).

The state has a predominantly agricultural economy and the main emerging sub sector within agriculture is fruit culture, which has earned Himachal Pradesh the name of "The Apple State of India". It is not an industrially developed state and all types of industrial enterprises contribute merely 7.5 per cent of the state's domestic product. The average per capita income of the state for the period 1991-92 was Rs. 5,355 (\$116.41). The proportion of the total population living below the poverty line in Himachal Pradesh was 9.2 per cent, much lower than the national average of 39.3 per cent of the country's population (Centre for Monitoring Indian Economy, 1994; Government of India, 1994).

Gender inequality in the state is fairly marked on indicators such as education, sex differentials in childhood mortality, and access to paid employment. Although, female literacy rates in the state have been steadily increasing in the last two decades, the rates still remain markedly lower than the male literacy rates. The literacy rates in the state in 1991 for males and females were 75.4 per cent and 52.1 per cent, respectively (Census of India, 1991). Women's participation in income generating activity was also very low and only 7.4 per cent of the women were recorded as economically active according to the 1991 census figures.

The sex ratio of the population (number of females per 1,000 males) for the year 1991 was 996 which is higher compared to India's figure of 927 . The patterns of sex differentials in the mortality rate provide evidence of the differential treatment of male and female children. The child mortality rate in the state was 44 per cent higher for females than for males according to the National Family Health Survey.

Sample:

Data for this study were drawn from a larger study conducted in the capital city of Shimla in 1996-97. The sample comprised of 204 boys and 213 girls drawn from various schools of Shimla town studying in 6th to 8 th class and the mothers of these boys and girls. The study was conducted in two phases. In the first phase the data were collected from the school children. In the second phase of the study the mothers were contacted and administered a detailed questionnaire which elicited information on a number of socioeconomic characteristics of the household, including age, education, and work status of the mother, age and education of the father, household income, marital duration, sex preferences as measured by the Coombs

Table 1. Socio Demographic Characteristics of Boys and Girls

\begin{tabular}{lccccc}
\hline & \multicolumn{2}{c}{ Boys $(N=204)$} & \multicolumn{2}{c}{ Girls $(N=213)$} & \multirow{2}{*}{$t$-value } \\
\cline { 2 - 5 } Background Characteristics & Mean & $S D$ & Mean & $S D$ & \\
\hline Age of child (Yrs.) & 12.2 & 11.43 & 12.1 & 13.41 & 1.12 \\
Son Preference & 4.66 & 1.25 & 4.78 & 1.08 & 1.03 \\
Mother's Age (Yrs.) & 37.31 & 4.41 & 35.87 & 3.67 & $3.64 * *$ \\
Mother's Education (Yrs.) & 8.47 & 4.81 & 7.81 & 4.81 & 1.40 \\
Mother's Employed (\%) & 6.8 & & 8.2 & & \\
Father's Education (Yrs.) & 12.21 & 3.30 & 12.04 & 3.08 & 0.54 \\
Household Income (Rs.) & 5160 & 2601 & 4915 & 2305 & 1.02 \\
\hline
\end{tabular}

$* * p<.01$ 
Index, number of sons, number of daughters, and number of children. The demographic and socio-economic characteristics of the two samples are presented in Table 1. The mean age of the boys and girls was 12.2 and 12.1, respectively. The two samples were also comparable on several socio-economic characteristics although the mothers of the boys were significantly older than the mothers of the girls. The mean sex preference scores were also similar for the two samples.

\section{RESULTS}

\section{Measures:}

Coombs Index: Son preference was measured by using the Coombs IS Index (Coombs, Coombs, \& McClelland, 1975), This index is a seven point scale and measures the sex preferences for children at the individual level. The scale ranges from IS 1 (a strong girl bias) to IS 7 (a strong boy bias), with IS 4 being a preference for balanced sex composition. The preference for balance means equal number of boys and girls and as suggested by the authors is not to be interpreted as indifference or an absence of sex bias. The Coombs Index has been used to measure sex preferences for children at the individual level in a number of developing countries (e.g., Coombs \& Sun, 1978; Ahmed, 1981; Karki, 1988).

Standard Progressive Matrices: The Standard Progressive Matrices (SPM, Raven, 1960) was used to measure the intelligence of children. Standard Progressive Matrices is a standardized and a valid measure of abstract intelligence. It has been frequently used to measure intelligence of children in India. The children's raw scores on SPM were converted into percentile ranks and then into $z$-scores to ensure comparability of scores across different ages of children.

Statistical Analysis: In order to identify the significant predictors of intelligence, stepwise multiple regression analyses were performed, separately for boys and girls. The predictor variables included mother's age, mother's education, mother's work status, father's age, father's education, household income, marital duration, preference for sons measured by the Coombs Index, number of brothers, number of sisters and number of siblings. The Beta coefficients and the corresponding $t$-value are of the final equation and the $F$-values mentioned in the Tables 2 and 3 were calculated for $R^{2}$ change at each step of the regression analysis.

The mean IQ of the boys $(M=0.17)$ was significantly $(t=3.9, d f=416, p<.01)$ higher than that of girls $(M=-0.11)$. The result of the regression analysis of different variables in terms of their importance in predicting the PM scores of boys is presented in Table 2. As is evident from the Table, the significant predictors of the PM scores of the boys were household income $(\beta=.34, t=5.23, d f=405, p<.01)$ and son preference $(\beta=.07, t=3.21$, $d f=405, p<.01)$ and both these predictor variables were positively correlated with the intelligence of boys. These two variables accounted for 17 per cent of the variance in the PM scores of the boys. Out of this, household income explained 11.9 per cent $(F=27.42$, $d f=405, p<.01)$ of the variance and the sex preferences for children contributed an additional 5 per cent $(F=12.23, d f=405, p<.01)$ of the variance in the PM scores of the 
Table 2. Stepwise Multiple Regression Analysis of Different Variables as Predictors of Intelligence Scores of Boys

\begin{tabular}{lcccccc}
\hline Independent Variable & $r$ & $\begin{array}{c}\text { Beta } \\
\text { Coefficient }\end{array}$ & $t$ & $R^{2}$ & $R^{2}$ Change & $\begin{array}{c}F \text {-value } \\
\left(R^{2} \text { change }\right)\end{array}$ \\
\hline Household Income & $.35^{* *}$ & .346 & $5.23^{* *}$ & .119 & .119 & $27.42^{* *}$ \\
Son Preference & $.32 * *$ & .074 & $3.21^{* *}$ & .170 & .050 & $12.23 * *$ \\
\hline
\end{tabular}

$* * p<.01$

Table 3. Stepwise Multiple Regression Analysis of Different Variables as Predictors of Intelligence Scores of Girls

\begin{tabular}{lrrrrrr}
\hline Independent Variable & $r$ & $\begin{array}{c}\text { Beta } \\
\text { Coefficient }\end{array}$ & $t$ & $R^{2}$ & $R^{2}$ Change & $\begin{array}{c}F \text {-value } \\
\left(R^{2} \text { change }\right)\end{array}$ \\
\hline Son Preference & $-.38^{* *}$ & -.382 & $6.01^{* *}$ & .146 & .146 & $36.09^{* *}$ \\
Mother's Education & $.31^{* *}$ & .194 & $2.87 * *$ & .178 & .032 & $7.81^{* *}$ \\
\hline
\end{tabular}

$* * p<.01$

boys. Thus, higher intelligence among boys was predicted by higher household income and higher preference for male children.

Table 3 presents the results of the regression analysis of different variables in terms of their importance in predicting the intelligence scores among girls. The results reveal that the significant predictors of the PM scores of the girls were son preference $(\beta=-38$, $t=6.01, d f=405, p<.01)$ and mother's education $(\beta=.19, t=2.87, d f=405, p<.01)$. These two variables accounted for 17.8 per cent of the variance in the PM scores of the girls. Out of this, son preference explained 14.6 per cent $(F=36.09, d f=405, p<.01)$ of the variance and mother's education explained an additional 3.2 per cent $(F=7,81, d f=405$, $p<.01$ ) of the variance in the PM scores of the girls. Thus, higher PM scores among girls were predicted by lower preference for male children and by higher levels of education among mothers.

\section{DISCUSSION}

The most noteworthy finding of the present study was that preference for sons among mothers was an important predictor of intelligence of both boys and girls, with higher preference for male children being positively correlated with the intelligence of boys and negatively correlated with the intelligence of girls. The results, therefore, support the hypothesis that preference for male children would enhance the intelligence of boys whereas it would hamper the intelligence of girls.

There are possibly several social, cultural, and economic reasons for these findings. At the social level, there operate various overt and covert differences between the 
experiences, expectations, and gender roles of male and female children (Eccles, 1987). Moreover, studies on value of children in India indicate that sons are desired for a wide variety of reasons which include continuity of family name, old age support, and financial help. In contrast, daughter's are perceived as an economic burden in view of their high marriage costs and their limited economic contribution (Jejeebhoy \& Kulkarni, 1989; Vlassoff, 1990; Malhi, 1993).

Bias against daughters in India is evident from several sources. Girls have been found to receive less food than boys (Sen \& Sengupta, 1983) and as a result the incidence and severity of both chronic and acute malnutrition is higher among girls than boys (Kielmann, Cecile, De Sweemer, Robert, \& Carl, 1983), girls also receive less medical care than boys, despite the fact that their diseases are less likely to last longer and be of more severe nature because of their poorer nutritional status (Wyon \& Gordon, 1971). Moreover, girls are less often taken for medical treatment than boys (Miller, 1988). A study of a South Indian village revealed that the expenditure on the treatment of first born girls was 35 percent of that spent on the treatment of first born boys (Beals, 1976). A particularly significant feature of gender discrimination in India is that it is highly selective and more pronounced among girls who have older sisters (Das Gupta, 1987). Studies have observed the deleterious impact of early malnutrition on the intelligence of children, particularly in developing countries (Galler, Ramsey, \& Forde, 1986; Ricciuti, 1993; Pollitt, Gorman, Engle, Martorell, \& Rivera, 1993; Sigman, 1995). Early malnutrition hampers mental growth and malnourished children are typically found to be less responsive to adults, less motivated to learn, and less active in exploration than their more adequately nourished counterparts.

It is postulated that there may be several pathways through which son preference operates to influence the intelligence of boys and girls. Future studies need to identify and quantify the impact of social, cultural, and family environmental variables through which preference for sons differentially influences the IQ of boys and girls. It is important to note that we have documented the differential impact of son preference on IQ scores of boys and girls in middle socio-economic status families. It is possible that the impact of son preference on the intelligence of children is even more pronounced in households living in poverty.

The results further indicate that household income and education of mother were both positively correlated with the PM scores of boys and girls. Several previous studies have documented that the socio-economic status of the family is by far the best environmental predictor of a child's intelligence (e.g., Misra, 1980; Jachuck, 1982). Our results extend these findings to highlight the role of family environmental variables such as stated son preference to be also an important predictor of intelligence, particularly in the developing countries.

This study raises several important questions which need further attention. First, are these results confined only to geographical areas where son preference is strong and pervasive? Secondly, do sex preferences for children have a differential impact on girls as a function of their birth order? Finally, what are the potentially modifiable factors in the household which may protect the girls from the deleterious impact of strong preference for 
male children? These questions offer a fertile area for future research.

In sum, it can be concluded that son preference has a moderate impact on the intelligence of children which seems to be mediated through several pathways. We do not yet, however, know the components of the family environment which contribute to these effects.

\section{REFERENCES}

Ahmed, N. R. 1981. Family size and sex preferences among women in rural Bangladesh. Studies in Family Planning, 12, 100-109.

Basu, A. M. 1989. Is discrimination in food really necessary for explaining sex differentials in childhood mortality? Population Studies, 43, 193-210.

Beals, A. R. 1976. Strategies of resort to curers in South India. In M. Leslie (Ed.), Asian medical systems. Barkelay: University of California Press.

Bouchard, T. J., Jr. 1987. Information about the Minnesota Centre for Twin and Adoption Research. Minneapolis: University of Minnesota.

Bouchard, T. J., Jr., \& Segal, N. L. 1985. Environment and IQ. In B. B. Wolman (Ed.), Handbook of intelligence: Theories, measurement, and applications. New York: Wiley.

Bouchard, T. J., Jr., Lykken, D. T., McGue, M., Segal, N. L., \& Tellegen, A. 1990. Sources of human psychological differences: The Minnesota study of twins reared apart. Science, 250, 223-228.

Bourne, K. L, \& Walker, G. M., Jr. 1991. The differential effect or mother's education on mortality of boys and girls in India. Population Studies, 45, 203-219.

Centre for Monitoring Indian Economy. 1994. Basic statistics relating to the Indian economy. Bombay: Centre for Monitoring Indian Economy.

Census of India 1991. Final population totals: Brief analysis of primary census abstracts, Paper 2 of 1992. New Delhi: Government of India.

Chalip, L., \& Stigler, J. W. 1986. The development of achievement and ability among Chinese children: A new contribution to an old controversy. Journal of Educational Research, 79, 302-307.

Chen, L. C., Huq, E., \& D'Souza, S. 1981. Sex bias in the family allocation of food and health care in rural Bangladesh. Population and Development Review, 7, 55-70.

Coombs, L. C., \& Sun, T. H. 1978. Family composition preferences in a developing culture: The case of Taiwan. Population Studies, 32, 43-64.

Coombs, C. H., Coombs, L. C., \& McClelland, G. H. 1975. Preference scales for number and sex of children. Population Studies, 29, 273-298.

Das Gupta, M. 1987. Selective discrimination against female children in rural Punjab, India. Population and Development Review, 44, 489-505.

Dyson, T., \& Moore, M. 1983. On Kinship structure, female autonomy, and demographic behaviour in India. Population and Development Review, 9, 35-60.

Eccles, J. S. 1987. Gender roles and women's achievement related decisions. Psychology of Women Quarterly, 11, 135-172.

Flynn, J. R. 1987. Massive IQ gains in 14 nations: What IQ tests really measure. Psychological Bulletin, 101, 171-191.

Galler, J. R., Ramsey, F., \& Forde, V. 1986. A follow-up study of the influence of early malnutrition on subsequent development: IV intellectual performance during adolescence. Nutrition and Behaviour, $\mathbf{3}$, 211-222.

Gottfried, A. W. 1984. (Ed.) Home environmental and early cognitive development. San Francisco: Academic. Government of India. 1994. Economic Survey 1993-94. New Delhi: Ministry of Finance, Economic Division. Gupta, S. C. 1986. Birth order, feeding care, and effectiveness of health education. Hygie, 5, 10-17.

Hossain, M. M., \& Glass, R. I. 1988. Parental son preference in seeking medical care for children less than five years of age in a rural community in Bangladesh. American Journal of Public Health, 78, 1349- 
1350.

Jachuck, K. 1982. Level I-Level II abilities of socially disadvantaged children: A test of cumulative deficit hypothesis. Perspectives in Psychological Researches, 5, 1-4.

Jejeebhoy, S. J., \& Kulkarni, S. 1989. Reproductive Motivation: A comparison of wives and husbands in Maharashtra, India. Studies in Family Planning, 20, 264-272.

Jencks, D. 1972. Inequality: A reassessment of the effect of family and school in America. New York: Basic Books.

Karki, Y. B. 1988. Sex preference and the value of sons and daughters in Nepal. Studies in Family Planning, 19, 169-178.

Kielmann, A. A., Cecile, De Sweemer, Robert, L. P., \& Carl, E. T. 1983. (Eds.). Analysis of morbidity and mortality. Child and maternal health services in rural India: The Narangwal experiment, Vol. 1. Baltimore: The Johns Hopkins University Press.

Kishore, S. 1995. Gender differentials in child mortality: A review of the evidence. In M. Das Gupta, L. C. Chen, \& T. N. Krishnan (Eds.), Women's Health in India: Risk and Vulnerability (pp. 19-54). Bombay: Oxford University Press.

Malhi, P. 1993. Impact of women's education on sex preferences, value and aspirations for children: Evidence from Haryana. Man and Development, 15, 46-62.

Malhi, P., Jerath, J. M., \& Puri, D. 1991. Women's status and childhood mortality in India. Man and Development, 13, 99-113.

Mankeker, K. 1988. Their struggle for equality has begun! Yojana, 32, 23.

Miller, B. D. 1989. Changing patterns of Juvenile sex ratios in rural India, 1961 to 1971. Economic and Political Weekly, 24, 229.

Miller, S. A. 1988. Parents beliefs about children's cognitive development. Child Development, 59, 259-285.

Misra, R. S. 1980. An exploration study of health and mental status of children. Child Psychiatry Quarterly, 13, 18-23.

Munsinger, H. A. 1978. The adopted child's IQ: A crucial review. Psychological Bulletin, 82, 623-659.

Plomin, R. 1989. Environment and genes: Determinants of behaviour. American Psychologist, 44, $105-111$.

Pollitt, E., Gorman, K. S., Engle, P. L., Martorell, R., \& Rivera, J. 1993. Early supplementary feeding and cognition. Monographs of the Society for Research in Child Development, 58 (Serial No. 235).

Raven, J. C. 1960. Guide to the standard progressive Matrices: Sets, A, B, C, D and E (Rev. ed.). London: Lewis and Co. Ltd.

Ravindran, S. 1986. Health implications of sex discrimination in childhood. A review paper and an annotated bibliography. Unpublished Paper.

Ricciuti, H. N. 1993. Nutrition and mental development. Current Directions in Psychological Science, 2, 43-46.

Sample Registrar System (SRS) 1992. Fertility and mortality indicators 1991. New Delhi: Ministry of Home Affairs.

Sen, A., \& Sengupta, S. 1983. Malnutrition of rural children and the sex bias. Economic and Political Weekly, 18, 855-864.

Sigman, M. 1995. Nutrition and child development: More food for thought. Current Directions in Psychological Science, 4, 52-55.

Vlassoff, C. 1990. The value of sons in an Indian village: How widows see it. Population Studies, 44, 5-20.

Weinberg, R. A. 1989. Landmark issues and great debates. American Psychologist, 44, 98-104.

Wyon, J. B., \& Gordon, J. E. 1971. The Khanna Study: Population problems in the rural Punjab. Cambridge, Mass: Harvard University Press. 